\title{
EREBEA
}

Revista de Humanidades

y Ciencias Sociales

Núm. 6 (2016), pp. 39-63

ISSN: 0214-0691

\section{LA LEYENDA NEGRA CONTRA ESPAÑA DURANTE EL ROMANTICISMO INGLÉS: LAS COLECCIONES BIOGRÁFICAS DE MARY HAYS*}

\author{
Begoña Lasa Álvarez \\ Universidad da Coruña
}

RESUMEN

En este trabajo se analizan las referencias a España en dos colecciones biográficas de la escritora inglesa Mary Hays: Female Biography (1803) y Memoirs of Queens (1821), pues en ellas aparecen varios hechos históricos en los que se ha fundamentado la llamada Leyenda Negra, como la Inquisición, las persecuciones de protestantes o la sospechosa muerte del infante Don Carlos. Lo cierto es que las mujeres españolas en estos textos son pocas; sin embargo, en las diversas biografías también aparecen otros personajes históricos, como Carlos V y Felipe II, y puesto que estos dos monarcas gobernaban un gran imperio, a ellos iba dirigida la mayor parte de la propaganda antiespańola de su tiempo y también mucha de la posterior. No obstante, dada la época en la que se publicaron las colecciones de Hays, ciertas pinceladas románticas son asimismo observables.

Palabras Clave

Mary Hays; biografías de mujeres; España, Leyenda Negra; Romanticismo.

Fecha de recepción: 29 de sept. de 2016 Fecha de aceptación: 30 de nov. de 2016

\section{Abstract}

This article will analyse the references involving Spain in two biographical collections by the English writer Mary Hays: Female Biography (1803) and Memoirs of Queens (1821), given that in these two texts there appear various historical events which are the main focus of the so called Black Legend, such as the Inquisition, the persecutions of Protestants and the suspicious death of the Infante Don Carlos. Indeed the Spanish women in these collections are scarce; however, in some of the biographies other Spanish historical figures also emerge, such as Charles V and Philip II, and since these two monarchs ruled a great empire, the greatest part of the anti-Spanish propaganda of their time and most of the subsequent one was addressed to them. Nevertheless, given the period of their publication, certain Romantic traces are also observable in Hays's collections.

\section{KeYwords \\ Mary Hays; women's biographies; Spain; Black Legend; Romanticism.}

* Este trabajo ha sido posible gracias al apoyo del grupo de investigación "Literatura y cultura inglesa moderna y contemporánea” (G000274) de la Universidade da Coruña. 



\section{Mary Hays y las Colecciones biográficas de mujeres}

Dada la creciente popularidad de la que gozaban las colecciones biográficas de mujeres célebres a principios del siglo XIX en Inglaterra, y en particular las creadas por escritoras, resulta hasta cierto punto lógico que la escritora inglesa Mary Hays (1759-1843) se embarcara en proyectos literarios de este género. Publicó en primer lugar Female Biography; or, Memoirs of Illustrious and Celebrated Women en $1803^{1}$, que se componía de seis volúmenes con 288 entradas de biografías de mujeres, y casi dos décadas más tarde, en 1821, Memoirs of Queens, Illustrious and Celebrated ${ }^{2}$, en la que, como su título indica, se centra únicamente en reinas, recopilando las biografías de 75 mujeres de la realeza. Este último texto se abre con un prólogo o prefacio en el que se revelan el propósito e ideario principales de esta escritora en sus colecciones biográficas:

Having more than once taken up my pen, how humble soever its efforts may have been, in the cause, and for the honour and advantage, of my sex; and having deeply at heart, as connected with the welfare of the human species, and of society at large, the moral rights and the intellectual advancement of woman, I acceded cheerfully, though declining in physical strength and mental activity, to the request of the publishers of the present volume, that I would select, compress, and compile, from the records of female eminence and worth, a memoir of Queens only, illustrious for their great qualities, or celebrated for their endowments and fortunes. The throne itself, with but few exceptions, secures not woman from the peculiar disadvantages that have hitherto attended her sex ${ }^{3}$.

Efectivamente, Hays se involucró en este proyecto cuando comenzó a sentir que sus fuerzas menguaban ya a los 61 años. De hecho esta fue su última obra publicada, aunque sobrevivió otros 20 años, y en ella, como en el resto de su producción escrita, trataba de mejorar la situación en la que se encontraban las

1 Mary Hays, Female Biography; Or, Memoirs of Illustrious and Celebrated Women, of All Ages and Countries. Alphabetically Arranged in Six Volumes. London: Richard Phillips, 1803.

2 Mary Hays, Memoirs of Queens, Illustrious and Celebrated. Londres: T. \& J. Allman, 1821.

3 Hays, Memoirs..., pp. v-vi. 
mujeres en su época, especialmente en lo que concernía a la educación, que ella consideraba insuficiente y desacertada.

La propia Hays era consciente de las carencias de su educación, que era el producto de su pasión por la lectura, aunque sin un método o fin específicos, y de la asistencia semanal a las iglesias no conformistas, además de la desinteresada ayuda académica de varios caballeros -amigos y mentores- a lo largo de su vida, como John Eccles, Robert Robinson, Josephe Priestley, Hugh Worthington, William Frend or William Godwin ${ }^{4}$. Este entorno resultó muy positivo para ella también, pues permitía a las mujeres alcanzar una mayor libertad de pensamiento y más oportunidades de participar en los debates y los movimientos culturales del momento 5 . El desarrollo intelectual de Hays, así como sus intereses literarios, le condujeron a participar públicamente de forma muy activa mediante la publicación primero de Letters and Essays, Moral and Miscellaneous (1793) y posteriormente de dos textos narrativos, Memoirs of Emma Courtney (1796) y The Victim of Prejudice (1799), en los que se aprecia claramente la denuncia de la situación de la mujer en su época y la reivindicación de sus derechos. Estos asuntos formaron parte también de los núcleos temáticos que desarrolló en otros trabajos, como su ensayo Appeal to the Men of Great Britain on Behalf of Women, escrito entre 1790 y 1791 , pero no publicado hasta 1798. Igualmente, y como ya se ha mencionado más arriba, esta es una de las líneas temáticas que guía los dos textos que se analizan en este trabajo.

Hays había comenzado a escribir vidas de mujeres ficticias en sus dos novelas, y posteriormente se adentró en la composición de vidas de mujeres reales. Lo hizo en primer lugar publicando la biografía de una sola mujer, la de su amiga y mentora Mary Wollstonecraft, cuyo obituario escribió para la prensa en 1800, y más tarde compilando las biografías de un conjunto amplio de mujeres, tanto en Female Biography, como en Memoirs of Queens. Así, al mismo tiempo que participaba en el gran avance que la historia de las mujeres había alcanzado ya en estos momentos, con sus escritos Hays pretendía que el gusto por la lectura de textos históricos fuese arraigando entre su público mayoritario, las mujeres ${ }^{6}$. El género biográfico en particular le proporcionaba además la posibilidad de responder a ciertas demandas de las lectoras de su época con respecto a los textos históricos, pues les resultaban aburridos al ocuparse únicamente de guerras y personajes

4 Gina Luria Walker, Mary Hays (1759-1843). The Growth of a Woman's Mind. Aldershoth, Hampshire: Ashgate, 2006, pp. 11-12.

5 Ruth Watts, "Introduction: Rational Dissenting Women and the Travel of Ideas", en Gina Luria Walker y Grayson M. Ditchfield (ed.): Intellectual Exchanges: Women and Rational Dissent, Enlightenment and Dissent, vol. 26 (2010), pp.1-27, p. 27.

6 Miriam L. Wallace, "Writing Lives and Gendering History in Mary Hays's Female Biography (1803)", en Eugene Steilzig (ed.): Romantic Autobiography in England. Farnham: Ashgate, 2009, pp. 63-78, p. 65. 
masculinos, como sugería Catherine Morland en un conocido pasaje de la novela Northanger Abbey de Jane Austen ${ }^{7}$. Sin embargo, las biografías conjugaban entretenimiento e instrucción y podían desarrollar el gusto por la lectura de contenidos históricos ${ }^{8}$, como esta autora inglesa manifestaba en otro de sus escritos, Letters and Essays, de 1793.

En cualquier caso, y como se ha indicado al comienzo de este trabajo, este tipo de texto se fue popularizando a lo largo del siglo XIX hasta convertirse en lo que se ha considerado como un fenómeno literario, aunque de carácter menor ${ }^{9}$. Asimismo, los diversos géneros históricos, incluyendo las biografías, se beneficiaron del interés por el pasado durante el Romanticismo, sin precedentes hasta este momento $^{10}$. Por otra parte, las colecciones biográficas de Hays participaban de una larga tradición en la que mediante diversos escritos biográficos se reivindicaba y defendía a mujeres valiosas y admirables, desde Christine de Pizan a Madame de Scudéry, entre otras, así como de la creciente voluntad editorial por la publicación de libros educativos y didácticos ${ }^{11}$, entre los que se encontraban los textos biográficos ${ }^{12}$.

Como se ha hecho mención más arriba, a pesar de tratarse de colecciones biográficas de mujeres, los dos textos que se analizan en este trabajo mantienen bastantes diferencias, especialmente en lo que se refiere al grupo de mujeres que se consideran en cada uno de ellos, pues a diferencia de Female Biography, Memoirs of Queens, como su título indica, pone el foco en las reinas; pero también por el volumen, pues el número de mujeres biografiadas y el de tomos de cada obra dista considerablemente. Además, hay que subrayar el hecho de que en la colección centrada en reinas, Hays se basa en gran medida en su compilación anterior, al reelaborar y resumir numerosas entradas ya publicadas en Female Biography. Sin embargo, como veremos posteriormente, incluyó biografías nuevas, y alguna de ellas de gran interés para este trabajo. Es por ello que se ha decidido trabajar con ambos textos, pues por la información que ofrecen se complementan uno a otro.

7 Jane Austen, Northanger Abbey, Barbara M. Benedict y Dreidre Le Faye (ed.), The Cambridge Edition of the Works of Jane Austen. Cambridge: Cambridge University Press, 2006, p. 110.

8 Citado en Mary Spongberg, "Mary Hays and Mary Wollstonecraft and the Evolution of Dissenting Feminism", en Gina Luria Walker y Grayson M. Ditchfield (ed.): Intellectual Exchanges: Women and Rational Dissent. Enlightenment and Dissent, vol. 26 (2010), pp. 230-258, p. 241.

9 Mary Spongberg, "Female Biography", en Mary Spongberg, Barbara Caine y Ann Curthoys (eds.): Companion to Women's Historical Writing. Basingstoke: Palgrave, 2005, pp. 172-182, p. 172.

10 Greg Kucick, "Romanticism and the Re-engendering of Historical Memory", en Matthew Campbell, Jaqueline M. Labbe y Sally Shuttleworth (eds.): Memory and Memorials 1789-1914. Literary and Cultural Perspectives. Londres y Nueva York: Routledge, 2000, pp. 15-29, p. 15.

11 William St Clair, The Reading Nation in the Romantic Period. Cambridge: Cambridge University Press, 2004, p. 275.

12 Spongberg, "Female Biography", p. 173. 


\section{EsPaña Y LAS ESPAÑOLAS EN LOS TEXTOS BIOGRÁFicos DE haYS}

Las biografías de mujeres españolas son pocas en relación al número total de biografiadas en los textos aquí analizados, nueve en Female Biography y cinco en Memoirs of Queens, aunque en realidad son once, pues hay tres reinas de origen español que aparecen en ambas colecciones. Destacan en primer lugar, como no podía ser de otro modo al tratase uno de los textos una colección de vidas de reinas, las biografías de varias soberanas de origen español. Algunas reinaron en otros países europeos, como "Brunehaut", Brunilda (c. 543-613), "Blanche of Castile", Blanca de Castilla (1188-1252) y "Anne of Austria", Ana de Austria (1601-1666), que fueron reinas consortes y regentes en Francia, y "Catherine of Arragon”, Catalina de Aragón (1485-1536), primera esposa de Enrique VIII de Inglaterra ${ }^{13}$. Sin embargo, cabe destacar en el grupo de monarcas a "Isabella of Castile", Isabel de Castilla (1451-1504), que Hays incluye como novedad en Memoirs of Queens, reina por nacimiento y también por derecho.

Junto a estas mujeres destacadas por su poder y por haber gobernado sus reinos, podemos agrupar a otras españolas en Female Biography de Hays que sobresalieron por su educación, conocimientos y sabiduría, aspectos que se subrayan en las biografías que de ellas ofrece la escritora inglesa. Se trata de "Isabella de Cordaud", Isabel Losa o de Córdoba (1491-1564), de la que no se indica su origen español, pero sí sus conocimientos en lenguas clásicas y antiguas, así como su doctorado en teología ${ }^{14}$. En el caso de "Isabella de Rosares", Isabel Roser, una dama española del siglo XVI, se incide en su elocuencia y su fama como predicadora ${ }^{15}$. Por lo que se refiere a la religiosa "Mary de Agreda", Sor María de

13 De forma muy gráfica se ha señalado también la particular Leyenda Negra que han tenido que sufrir las reinas regentes, al ser habitualmente juzgadas severamente tanto por su imagen política como personal. Véase Laura Oliván Santaliestra, "Ángeles o demonios: La Leyenda Negra de las reinas regentes en la historiografía del siglo XIX", en Arenal, vol. 11, no 1 (2004), pp. 153173. En este sentido, Hays era muy consciente de esta situación de impotencia y debilidad de las reinas regentes, a las que se atacaba no sólo como gobernantes, sino también como mujeres y madres (Memoirs...69), es por ello que afirma que la regencia "is too frequently a stormy period, [...] gloomy and turbid" (Memoirs...27). Además, no hay que olvidar que las reinas regentes eran también extranjeras en una corte extraña, por lo que tenían que sufrir los celos de otros príncipes y nobles (Memoirs...68). Sin embargo, en los textos aquí analizados todas estas regentes aparecen como eficientes y dignas de admiración y respeto (Memoirs...70; Female...I, p. 139), aun cuando tuviesen que luchar en contra de su propio país de origen, como le ocurrió a Ana de Austria ( $\mathrm{Fe}$ male... I, p. 139).

14 Hays, Female...IV, p. 434.

15 Hays, Female...III, p. 424. En la biografía de Roser se ofrecen datos de otra mujer, coetánea suya, Isabel Josa, también catalana y seguidora como la anterior de Ignacio de Loyola. Hays no hace sino reflejar una confusión ya presente en las fuentes que utiliza y que continuará posteriormente. Véase María Jesús Lorenzo Modia, "The Contribution of Isabella de Rosares and Isabella de Josa to the Development of Women's Learning in the Sixteenth Century", en G. Luria Walker (ed.): The Invention of Female Biography. Londres: Routledge, 2016. En prensa. 
Agreda (1602-1665), Hays se centra en su faceta como escritora y en su obra más conocida, Mistica Ciudad de Dios, pues fue la causa de importantes debates teológicos en la Sorbona de París ${ }^{16}$. Finalmente, "Aloysia Sigea of Toledo", Luisa Sigea (1522-1560) llamó también la atención de Hays, quien en una breve biografía de la humanista española señala su dominio de varias lenguas y su faceta como escritora ${ }^{17}$. Por último, junto a los conocimientos y la educación, otros motivos por los que algunas mujeres españolas merecen figurar en la colección de Hays son su valor y coraje. En este grupo se insertan "Maria d'Estrada”, María de Estrada, que vivió entre finales del siglo XV y el XVI, y de la que se subraya la intrepidez que demostró acompañando a su marido en la conquista de México por Cortés ${ }^{18}$; y a "María Pacheco Padilla” (1497-1531), esposa de Juan de Padilla, que al enviudar gobernó y lideró la resistencia comunera durante las Guerras de las Comunidades de Castilla contra el emperador Carlos. ${ }^{19}$

Además, dada la dimensión cosmopolita e internacional de la monarquía a lo

16 Hays, Female...I, pp. 32-36.

17 Hays, Female...I, p. 271. En este apartado de las mujeres eruditas cabría añadir la biografía de "Juana Inez de la Cruz", Sor Juana Inés de la Cruz, que nació y vivió en México en unas fechas en las que este territorio era parte de la Corona española. Aunque en su breve semblanza se incide en la educación y sabiduría de esta mujer, se señala que fue admirada por personajes ilustres de la vieja y nueva España, distinguiendo así la metrópoli de los nuevos territorios colonizados (Female...III, pp. 442-446). Por otra parte, al tratarse de un asunto que interesaba de forma especial a Hays, la educación de las mujeres como un rasgo necesario y que contribuía a su completa formación, aparece también en las biografías de las reinas españolas mencionadas. En las cortes y entre las familias nobles, la cultura y las artes se cultivaban de forma prominente, y tanto hombres como mujeres participaban con asiduidad en estas actividades. Las cortes en particular destacaban por la práctica conjunta de las armas y las letras, por lo que las mujeres de la realeza disponían de un espacio más amplio en el que actuar, e incluso si su carácter y sus habilidades se lo permitían podían llegar a ser el centro del mismo. Así, las princesas recibían una educación muy completa que incluía un amplio conocimiento en lenguas clásicas y modernas, en literatura, música, artes, y otras destrezas cortesanas, como la caza o el baile. De tal modo que su aprendizaje les preparaba para desempeñar su rol como consortes en otras cortes extranjeras. Es el caso de Blanca de Castilla cuando llegó a Francia, pues "the talents and beauty of Blanche rendered her the ornament and admiration of the court" (Female... I, p. 398). Por lo que se refiere a Catalina de Aragón, Hays da comienzo a su biografía en ambos textos resaltando su educación, que junto a la de sus hermanas era bien conocida en su época (Memoirs... p. 133; Female...II, p. 151). Como una dama instruida del Renacimiento, esta reina será posteriormente la encargada de educar a su propia hija, María Tudor, que dispuso de tutores como el español Juan Luis Vives, que le enseñó la lengua latina (Female... II, p. 152). Catalina también actuó como mecenas de este y de otros conocidos intelectuales de este periodo, como Erasmo. En la biografía de la reina María Tudor se pueden observar los frutos de la educación que le proporcionó su madre, pues es esta faceta la única que merece una calificación positiva por parte de Hays. Se destacan sus conocimientos en latín, lengua que traducía y escribía con buen estilo (Memoirs... 374). Para más información sobre este tema véase, entre otros, Kathleen Wellman, Queens and Mistresses of Renaissance France. New Haven y Londres: Yale University Press, 2013.

18 Hays, Female...IV, p. 325.

19 Hays, Female...IV, pp. 33-37. 
largo de la historia europea, se menciona a España en otras biografías de mujeres, especialmente en las de varias reinas. Así, serán dos soberanos españoles, Carlos $\mathrm{V}$ y Felipe II, quienes se asomen en algunas de las entradas de estas colecciones. Estos dos monarcas se inspiraron en sus antecesores, los Reyes Católicos, y mantuvieron gran parte de sus ideales, centrándose en mantener su fe ardientemente y en encabezar toda la cristiandad ${ }^{20}$, lo que causó importantes rivalidades y conflictos con otros reinos europeos, especialmente Inglaterra y Francia. El papel desempeñado por las figuras masculinas es obviamente secundario, pues las protagonistas son las mujeres; sin embargo, aportan ciertos rasgos y actitudes personales y públicas que habitualmente contrastan con un retrato más positivo de las mujeres biografiadas. Esto concuerda con el deseo de la escritora inglesa de denunciar el doble rasero con el que eran juzgadas las mujeres en su época, cuando los hombres - invariablemente los principales jueces - no destacaban precisamente por sus virtudes. Como ella misma manifestaba, ni siquiera ostentar el poder y ser reina liberaba a las mujeres de las desventajas propias de su sexo. Esto lo pudo observar Hays en la sociedad inglesa de su época y se puede decir que fue una de las causas que desencadenaron la elaboración y publicación de su colección de biografías de reinas. Hays vivió el acceso al trono de Jorge IV, que propició un conflicto matrimonial, conocido como "Queen Caroline Affair", que sacudió la opinión pública inglesa justo un año antes de la aparición de Memoirs of Queens de Hays ${ }^{21}$.

\section{La Leyenda Negra y la época Romántica}

Evidentemente, Hays trata diversos acontecimientos de la historia de Espańa en estas y otras biografías de ambos textos, y algunos de ellos se relacionan con lo que se conoce como Leyenda Negra que, desde su primera definición por Julián Juderías en $1914^{22}$, ha sido considerada tradicionalmente como una inter-

20 Peggy K. Liss, "Isabel, Myth and History", en David A. Baruchoff (ed.): Isabel la Católica, Queen of Castile: Critical Essays. Basingstoke, Hampshire: Palgrave, pp. 57-78, 2003, p. 67.

21 Los editores de este libro, T. \& J. Allman, que se muestran en la portada como impresores de Su Majestad, se lo encargaron a Hays anticipando los altos ingresos que podían conseguir como consecuencia de la notoriedad del escándalo real. Cuando el rey Jorge IV accedió al trono en 1820, su mujer, Carolina de Brunswick, que había estado viviendo en el extranjero, volvió para reclamar sus derechos como reina. El rey no quiso acceder a sus demandas y pidió al Parlamento que le concediera el divorcio en base al adulterio de su mujer. La decisión del impopular rey, que además de ser mujeriego había despilfarrado toda su fortuna, provocó el juicio público de la reina en el Parlamento. La prensa se ocupó a diario de todos los detalles escabrosos del proceso, pero el pueblo británico apoyó mayoritariamente a la reina Carolina. Véase, entre otros, Anna Clark, "Queen Caroline and the Sexual Politics of Popular Culture in London, 1820", en Representations, vol. 31 (1990), pp. 47-68; Mary Spongberg, "The Ghost of Marie Antoinette: A Prehistory of Victorian Royal Lives", en Lynette Felber (ed.): Clio's Daughters. British Women Making History, 1790-1899. Newark: University of Delaware Press, 2007, pp. 71-96, p.86-91.

22 Este autor publicó en 1914 su libro titulado La leyenda negra y la verdad histórica, que se ree- 
pretación sobre España que ha aparecido y reaparecido a lo largo de las últimas cuatro centurias en Gran Bretańa y otros países europeos, cada vez que resultaba conveniente o necesario denigrar la naturaleza o las iniciativas de los españoles ${ }^{23}$. Juderías lo explicaba así:

entendemos por leyenda negra, la leyenda de la España inquisitorial, ignorante, fanática, incapaz de figurar entre los pueblos cultos lo mismo ahora que antes, dispuesta siempre a las represiones violentas; enemiga del progreso y de las innovaciones; o, en otros términos, la leyenda que habiendo empezado a difundirse en el siglo XVI, a raíz de la Reforma, no ha dejado de utilizarse en contra nuestra desde entonces y más especialmente en momentos críticos de nuestra vida nacional ${ }^{24}$.

Sin embargo, con el paso del tiempo se ha ido revisando este concepto, e historiadores como García Cárcel consideran que no ha existido una crítica negativa intencionada contra España desde el extranjero, sino una imagen que España ha visto de lo que los demás veían de ella; se trata de una caracterización peyorativa del otro, normalmente un rival, pero que no se ha producido con exclusividad en relación a España ${ }^{25}$. En este sentido, Joseph Perez se pregunta si efectivamente existió esta Leyenda Negra o "si no entrará más bien en la categoría de las naciones que, después de haber ocupado el primer puesto en el mundo, se han visto obligadas a renunciar a una parte de sus ambiciones y sus pretensiones y entonces han sentido la amargura de haber sido mal comprendidas, primero, y después, relegadas a segundo plano"26. Por otro lado, Molina Martínez, en su revisión actual de esta noción, señala la dificultad de su definición, tanto por los problemas historiográficos que entraña, como por la interferencia de diversas

ditó con un título más corto, simplemente La leyenda negra en 1917. Se publicó una nueva edición años después por la Junta de Castilla y León, en 1997, en su colección "Libros recuperados", con el título de La leyenda negra. Estudios acerca del concepto de España en el extranjero. En realidad, el término Leyendo Negra se acuñó con anterioridad y fue utilizado por varios autores en las primeras décadas del siglo XX para referirse a la consideración negativa que los extranjeros tenían de España dentro de una corriente ideológica pesimista como consecuencia de una época de crisis. Fue en concreto la escritora gallega Emilia Pardo Bazán, quien utilizó por primera vez este término en una conferencia pronunciada en 1899 para oponerlo a la leyenda aurea. Véase Luis Español Bouché, "Los orígenes de la expresión 'leyenda negra”, en Asturias liberal, 11 nov. 2007.

23 William S. Maltby, La Leyenda Negra en Inglaterra. Desarrollo del sentimiento antihispánico. 1558-1660. México: Fondo de Cultura Económica, 1982, p. 9.

24 Julián Juderías, La leyenda negra. Estudios acerca del concepto de España en el extranjero. $2^{\mathrm{a}} \mathrm{ed}$. Valladolid: Junta de Castilla y León, 2003, p. 24.

25 Ricardo García Cárcel, La leyenda negra. Historia y opinión. Madrid: Alianza Editorial, 1998, pp. 14-16.

26 Joseph Perez, La leyenda negra. Madrid: Gadir, 2012, p. 16. 
cuestiones político-ideológicas ${ }^{27}$. Tal vez sea esta la causa de la atracción que ha ejercido este tema en estudiosos de diversas disciplinas a lo largo del tiempo, y también en la actualidad, pues se ha observado un notable avance en los trabajos de investigación que se centran en la Leyenda Negra en las primeras décadas del siglo XXI, tanto en el número como en los diversos enfoques empleados ${ }^{28}$.

Los orígenes de la Leyenda Negra en contra de España se remontan según los diversos investigadores a la época en que la Corona de Aragón comenzó a ocupar una posición hegemónica en Italia ya en el siglo XII, antes incluso de que Castilla y Aragón se unieran con los Reyes Católicos. Esta expansión hacia el Este de catalanes y aragoneses se mantuvo ininterrumpidamente casi hasta el siglo XVIII, y como consecuencia hubo episodios de hostilidad que desencadenaron los ataques y burlas de los italianos. Posteriormente, la rivalidad más acusada se trasladó a los Países Bajos, territorios bajo el dominio del emperador Carlos V como jefe de la Casa de los Habsburgo. Este conflicto de intereses políticos y religiosos se mantuvo durante el reinado de su hijo Felipe II, que tampoco estaba dispuesto a renunciar a estas provincias. Por lo que se refiere a las islas británicas, la propaganda antiespańola surgió en un momento en que por primera vez en su historia accede al trono una mujer, María Tudor, y se extiende el supuesto de que su dinastía podía correr peligro con la presencia de un monarca extranjero, al haberse casado la reina inglesa con un poderoso monarca espańol, Felipe II. Sin embargo, todo ello se enmascaró con motivaciones religiosas, por la persecución sufrida por los protestantes ingleses que no querían volver a la religión tradicional, cuando en realidad la mayoría de la población en esta época era aún católica ${ }^{29}$. Así, el conjunto de países reformistas europeos se unieron para descalificar a los católicos, en aquel momento encabezados por la potencia española, que también se había extendido ya por tierras del nuevo continente. La presencia española en América agudizó más si cabe las críticas, a raíz sobre todo de la publicación del tratado de Fray Bartolomé de las Casas, Brevisima relación de la destrucción de las Indias, en 1552, en el que denunciaba el maltrato sufrido por la población nativa de América a manos de los conquistadores y colonos españoles, puesto que sirvió para amplificar la ya mala imagen de España en el exterior.

27 Miguel Molina Martínez, "La Leyenda Negra revisitada: la polémica continúa", en Revista Hispanoamericana. Revista Digital de la Real Academia Hispano Americana de Ciencias, Artes y Letras, vol. 2 (2012), Disponible en: < http://revista.raha.es/>. 09/07/2016.

28 Antonio Sánchez Jiménez, "La Leyenda Negra: Para un estado de la cuestión”, en Yolanda Rodríguez Pérez y Antonio Sánchez Jiménez (eds.): España ante sus críticos: Las claves de la leyenda negra. Madrid y Frankfurt: Iberoamericana - Vervuet, 2015, pp. 23-44.

29 Alexander Samson, "A vueltas con los orígenes de la Leyenda Negra: la Inglaterra mariana", en Yolanda Rodríguez Pérez y Antonio Sánchez Jiménez (eds.): España ante sus críticos: Las claves de la leyenda negra. Madrid y Frankfurt: Iberoamericana-Vervuet, 2015, pp. 91-115. 
El hecho de que haya existido esa Leyenda Negra contra España puede no resultar del todo clara, como hemos visto; sin embargo, si bien esa visión peyorativa podía ser fruto de la rivalidad entre países que querían detentar el liderazgo en el continente europeo, no deja de resultar patente en textos de principios del siglo XIX, como herencia de lo que manifestaron sobre España en tiempos anteriores y en particular durante la centuria previa los filósofos franceses, con los que esa percepción despreciativa adquiere indudable relevancia ${ }^{30}$. Frente a esto y tras la Guerra de la Independencia, al adquirir España una mayor presencia en el imaginario europeo, los viajeros románticos incluyen la península en sus tours europeos y se extiende una nueva imagen de este país que coincide con lo que se ha denominado el mito romántico. España se identifica con una variedad de personajes populares y especialmente atractivos, sobre todo andaluces, unos héroes y heroínas justicieros y pintorescos que son portadores de virtudes, más que defectos ${ }^{31}$. En Gran Bretaña influyó en este cambio de perspectiva fundamentalmente el levantamiento de los españoles contra el ejército napoleónico y por tanto, el hecho de compartir el mismo bando. Pero además, intervinieron otros factores, como la presencia de exiliados españoles en su tierra o el interés por temas hispánicos de algunos autores románticos como Walter Scott, Lord Byron y William Wordsworth ${ }^{32}$. Así pues, los textos de Hays, escritos a caballo entre estos dos períodos, la Ilustración y el Romanticismo, expresan ambas tendencias, aunque como ya veremos, muestran una mayor presencia de las diferentes cuestiones que se han señalado tradicionalmente como centrales de la Leyenda Negra contra España, como son las relacionadas con la Inquisición y los antagonismos de tipo religioso y con los dos monarcas españoles del siglo XVI, momento en que España era la mayor potencia europea, el emperador Carlos $V$ y Felipe II. Todos ellos integran lo que se conoce como la Leyenda Negra europea, frente a la americana, que se centra en la conquista y colonización de América por los españoles y las consecuencias para la población nativa, de la que también se dará cuenta.

30 Juderías, La leyenda negra, pp. 236-243; García Cárcel, La leyenda negra, pp. 155-166.

31 Emma Carrere-Lara, "La crueldad ibérica a través de los relatos de viaje franceses del siglo XVIII", en Cuadernos dieciochistas, vol. 7 (2006), pp.245-256, p. 256.

32 Enrique Moradiellos, "Más allá de la Leyenda Negra y del Mito Romántico: el concepto de España en el hispanismo británico contemporaneista", en Ayer, vol. 31 (1998), pp. 183-199. Fernando Durán López, "La península para uso de ingleses: libros de materia española, 1800-1850", en Cuadernos de Ilustración y Romanticismo, vol. 18 (2012), pp. 1-7. Diego Saglia, Poetic Castles in Spain: British Romanticism and Figurations of Iberia (Amsterdam: Rodopi, 2000), pp. 11-12. 


\section{Mary Hays y la Leyenda Negra}

\subsection{La Inquisición}

Como consecuencia de las fuentes utilizadas por Hays, en su mayoría británicas y francesas ${ }^{33}$, esta escritora reproduce prejuicios y estereotipos sobre España y los espańoles, encarnados principalmente en la figura de Felipe II. Sin embargo, también retoma otros temas muy populares durante el Romanticismo británico, como la Inquisición, redescubierta y desarrollada con asiduidad en el género gótico. Para comprobar el tratamiento que Hays hace del tema de la Inquisición, resulta de sumo interés la biografía de la reina Isabel la Católica, una nueva incorporación de esta autora en Memoirs of Queens con respecto a su colección anterior Female Biography. Da así comienzo un interés creciente por esta figura en la historiografía anglosajona del siglo XIX, y que se relaciona con el acceso de otra mujer al trono de Gran Bretańa ${ }^{34}$. Se da la circunstancia de que para la fecha en que se publicó esta colección de biografías reales era cada vez más evidente que la heredera al trono británico iba a ser una mujer, dado que el rey Jorge IV había tenido únicamente una hija, Victoria. Así, la figura de la reina española resultaba útil y ventajosa, pues una soberana reinante era una figura imprecisa y de difícil definición en una sociedad patriarcal como la de entonces ${ }^{35}$. Es por este motivo también que se produjo el florecimiento de este género, que se centraba en las biografías de mujeres en roles de gobierno y con poder de decisión, tratando así de situar a la nueva reina británica como una integrante más de una estirpe de mujeres poderosas y con capacidad para ejercer sus obligaciones. Fueron precisamente las escritoras quienes se mostraron más atraídas por estas mujeres en una posición ambigua y paradójica, al ejercer al mismo tiempo como agentes públicos y privados en sociedad ${ }^{36}$. La reina castellana es un claro ejemplo de ello y resulta revelador que Hays inicie su biografía no con los habituales datos sobre su nacimiento y linaje, sino mencionando el carácter de su hermanastro Enrique IV, indolente y libertino ${ }^{37}$, subrayando así la necesidad de un gobernante eficaz y poderoso para Castilla como Isabel.

33 Mary Spongberg, "Appendix 2. The Sources of Female Biography", en Gina Luria Walker (ed.): Female Biography; or, Memoirs of Illustrious and Celebrated Women, of All Ages and Countries. Alphabetically Arranged. Londres: Pickering \& Chatto, 2014, vol. VI, pp. 535-544.

34 David A. Baruchoff, "Introduction: Instructions for Sainthood and Other Feminine Wiles in the Historiography of Isabel I", en David A. Baruchoff (ed.): Isabel la Católica, Queen of Castile: Critical Essays. Basingstoke, Hampshire: Palgrave, 2003, pp. 1-23, p.1.

35 Anne J. Dugan, ed., Queens and Queenship in Medieval Europe. Woodbridge: The Boydell Press, 1997, p. xx; Rohan A. Maitzen, Gender, Genre, and Victorian Historical Writing. New York: Garland, 1998, p. 162.

36 Rosemary Mitchell, Picturing the Past: English History in Text and Image 1830-1870. Oxford: Clarendon, 2000, p. 142.

37 Hays, Memoirs... p. 326. 
A pesar de que el gobierno conjunto de Isabel y su esposo Fernando de Aragón es caracterizado de forma positiva por su prudencia y honestidad, y su política general como sabia y necesaria ${ }^{38}$, el tono cambia completamente en una larga sección de esta biografía en la que se censura gravemente el tribunal de la Inquisición, y a los reyes católicos por ser los creadores del mismo. Se trata del párrafo más interesante de esta entrada, pues no se centra en la Inquisición como institución en el periodo en que reinaron estos monarcas, sino que es una descripción de todas las terribles consecuencias ocasionadas por la misma:

But no times, no disorders, could excuse the erection of a tribunal, the joint product of ignorance and bigotry, in itself a greater curse and scourge to mankind than the most ferocious violence of the most barbarous party rage. War and anarchy are in their nature of limited duration, but the iron weight of despotism, of a despotism more especially at once civil and spiritual, extending to the feelings of the heart and to the thoughts of the mind, undefined in its limits, mysterious in its operations, against which justice would plead in vain, and from which innocence has no appeal, is, of all engines of human invention, that which is most tremendous in its consequences, most appalling to the apprehension, and most paralyzing to the faculties. No virtues can redeem the memory of the founders of the INQUISITION, no talents abate the detestation with which their names and reign must ever be associated. The fall of that accursed institution, which the progress of reason has quietly undermined and levelled with the dust, would not have been too dearly purchased by all the horrors which disgraced the French revolution. Even the Bastile was, in comparison with its degrading and barbarous consequences, but as a passing cloud to the extinction of the light of the sun. In 1480, this diabolical tribunal, which continued to afflict the world for four centuries, was established by the blind and bigoted zeal of Ferdinand of Aragon and Isabella of Castile. $^{39}$

En primer lugar, para explicar la presencia de esta larga argumentación en el texto de Hays se hace necesario señalar que como prueban las alusiones a España -la nación católica por excelencia- en cualquiera de las entradas de ambas colecciones, las cuestiones religiosas se sitúan siempre en primer plano. En efecto, en la época en que escribió Hays sus obras se podía observar una preocupación 
creciente por el avance del catolicismo en las islas británicas, a consecuencia de las demandas de los católicos por la emancipación religiosa. Ciertos protestantes intransigentes comenzaron a utilizar el tribunal de la Inquisición para atacar el catolicismo, y la segunda década del siglo XIX fue particularmente productiva en cuanto a publicaciones sobre esta cuestión. Se reeditaron textos antiguos como la traducción de Historia Inquisitionis (1692) de Philip Limborch publicada en 1816, y se publicaron nuevas ediciones de la traducción al inglés de la Relation de l'Inquisition de Goa (1687) de Charles Dellon en 1812 y $1815^{40}$. En esta misma década también se tradujo y publicó en inglés uno de los textos más influyentes en contra de la Inquisición escritos por un español, The Inquisition Unmasqued (1813) de Antonio Puigblanch, e igualmente decisiva resultó la presencia en la prensa inglesa de fragmentos y reseñas de este texto, junto a la información que se ofrecía de otro tratado muy destacado sobre este tema, Histoire critique de l'Inquisition d'Espagne de Juan Antonio Llorente (1817-1818). Por lo tanto, el público británico tenía cierto conocimiento y estaba familiarizado con el tema de la Inquisición, que fue explotado simultáneamente en la literatura y en particular en el género gótico, por autores y autoras de la talla de Matthew G. Lewis, Ann Radcliffe, William Godwin y Charles Maturin ${ }^{41}$. Precisamente Hays presenta una imagen de la Inquisición que encaja casi a la perfección con las convenciones que se manejaban en las obras literarias, al mencionar el sadismo, el misterio, o su poder absoluto ${ }^{42}$. En suma, la cuestión católica podía surgir en relación a cualquier asunto en estos momentos en Gran Bretaña y al continuar siendo España el país que representaba con mayor afán esta fe resultaba el blanco apropiado de todas las opiniones interesadas al respecto ${ }^{43}$. Todo ello demuestra el papel trascendental que juega la religión a la hora de forjar identidades nacionales, es decir que, como apunta Linda Colley, un pueblo podría definirse como una nación no por un consenso político o cultural propio, sino más bien en reacción a un Otro más allá de sus fronteras, o como en este caso orillas, y ese Otro muy bien podría encarnarse en una nación católica militante ${ }^{44}$, como ocurre en este caso con España.

Por otra parte, cabe señalar que a Hays, por su propia condición de disidente de la iglesia anglicana y por su relación con círculos radicales, este problema le

40 Daniel Muñoz Sempere, La Inquisición española como tema literario. Politica, historia y ficción en la crisis del Antiguo Régimen. Woodbridge, Suffolk: Tamesis, 2008, p. 133.

41 Saglia, Poetic Castles, pp. 43-45; Doris Moreno, La invención de la Inquisición. Madrid: Marcial Pons, 2004, pp. 174-175.

42 Daniel Muñoz Sempere, "Góticos, traductores y exiliados: La literatura sobre la Inquisición española en Inglaterra (1811-1827)”, en Cuadernos de Ilustración y Romanticismo, vol. 13 (2005), pp.141-169, p.146.

43 David Howarth, The Invention of Spain. Cultural Relations between Britain and Spain 17701870. Manchester y Nueva York: Manchester University Press, 2007, pp. 59-61.

44 Linda Colley, Britons. Forging the Nation 1707-1837. Londres: Pimlico, 2003, pp. 6-7. 
interesaba e inquietaba más si cabe, pues sus convicciones religiosas la conducían a un compromiso radical con la independencia de criterio y con el orden moral, que incidían en su profunda creencia en la reforma religiosa y política ${ }^{45}$. En este sentido, Hays y el resto de sus colegas y amistades que compartían sus mismos círculos intelectuales abogaban por una mayor tolerancia religiosa y la separación entre Iglesia y Estado ${ }^{46}$. Prueba de ello es lo que la propia escritora inglesa declara sobre esta cuestión en otro de sus textos: "So long as Christianity is kept distinct from civil polity, it will fall like a rich dew, fructifying and fertilizing the human character", y a continuación, en relación al catolicismo añade: "Priestcraft [...] is a creature of the state, dissolve the unnatural union, and its terrors vanish into thin air"" 47 .

\subsection{Carlos $V$}

El nieto de la reina Isabel de Castilla, el emperador Carlos V (1500-1558) aparece en la biografía de su tía Catalina de Aragón, cuando Hays señala que el papa Clemente estaba interesado en posicionarse de parte del esposo de Catalina, el rey Enrique VIII de Inglaterra, pero "Catherine was protected in her claims by the emperor; and the politics of the pope, who depended upon the empire, became embarrassed and fluctuating" ${ }^{48}$. El papel ejercido por el papa y por el emperador en todas las circunstancias que condujeron al cisma de Inglaterra con la Iglesia de Roma se explican en la biografía de esta reina, así como todas las gestiones llevadas a cabo por Wolsey, uno de los consejeros de Enrique, que no fue capaz de conseguir que Roma aceptara el divorcio del rey, pero tampoco el papado para sí mismo ${ }^{49}$. Tanto en Female Biography como en Memoirs of Queens Enrique VIII es el protagonista de la biografía de su esposa Catalina de Aragón y se explican de forma bastante detallada las circunstancias que le llevaron a romper con la autoridad papal y declarase cabeza de la Iglesia de Inglaterra, motivo por el que se convertirá este país en antagonista religioso del resto de Europa y en particular de España, pues en estos momentos era quien encabezaba el poder católico en el continente. Sin embargo, Hays no simpatizaba con este monarca, al que llama tirano en varias ocasiones, y sugiere otras posibles causas para el rechazo y divorcio de Enrique de Catalina, como, además de la falta de un heredero varón, el envejecimiento de la reina y el encaprichamiento del rey por una rival joven y hermosa, Ana Bolena. ${ }^{50}$

45 R. Watts, "Introduction: Rational Dissenting Women and the Travel of Ideas", en Luria Walker y Ditchfield (eds.), vol. 26 (2010), pp. 1-27, p.13.

46 Luria Walker, Mary Hays, p. 67.

47 M. Hays, Letters and Essays, Moral, and Miscellaneous. Londres: T. Knott, 1793, pp. 9-10.

48 Hays, Memoirs... p. 135.

49 Hays, Female... II, pp. 160-161.

50 Hays, Memoirs... pp. 134-5. 
Carlos V vuelve a aparecer en la biografía de su hermana María, reina de Hungría (1505-1558). La valía e influencia de esta mujer sobre el emperador se resaltan desde las primeras líneas de su biografía: "She was consulted by the emperor her brother, who placed in her entire confidence, on all political affairs, and to her sagacity and prudence he avowed himself indebted" ${ }^{\prime \prime}$. Carlos tenía que gobernar sobre un vasto territorio y buscó la ayuda de algunos miembros de su propia familia en los que confiar, como su hermana María. Pero si por algo destaca esta reina en su biografía es por unos acontecimientos relacionados nuevamente con la religión: "what is more to her honour, she sought to ameliorate the fate of the Flemish protestants, whom the court of Spain persecuted. The imperial laws by which heretics were condemned to death were mitigated at the request of the queen of Hungary" 52 . Se hace referencia explícita así a uno de los episodios más señalados por los estudiosos como desencadenante y desarrollador de la Leyenda Negra en contra de España: la orden decretada por el emperador Carlos en 1529 en la que se establecía el castigo de pena de muerte a todos los herejes de los Países Bajos, por entonces territorio bajo el dominio del imperio ${ }^{53}$.

\subsection{Felipe II}

Los conflictos y controversias en Flandes empeoraron en la segunda mitad del siglo XVI, cuando el sucesor de Carlos, su hijo Felipe II (1527-1598), mandó allí al Duque de Alba para intentar controlar la situación. Este estableció un tribunal especial, el Consejo de los Disturbios, más conocido como el Tribunal de Sangre, dado el elevado número de personas que fueron sentenciadas y ejecutadas ${ }^{54}$. Tal vez por ello, al final de la biografía de María de Hungría, Hays se refiera a estos acontecimientos, que representan la intolerancia de los católicos españoles, al aludir explícitamente a este monarca y afirmar que: "Philip II, who succeeded to her and to his father, made the loss of both to be more deeply felt and regretted" ${ }^{5}$. El desarrollo e importancia de la imprenta en los Países Bajos provocó la expansión y circulación de una imagen negativa de España mediante la publicación de algunos textos en contra de su fanatismo religioso; de este modo la idea de Espańa como una nación en contra de la libertad religiosa y política se difundió por todo el continente, y cuajó especialmente en la Inglaterra isabelina y la Francia hugonote, contribuyendo así a la progresión de la Leyenda Negra. Entre estos escritos destaca la Apologie ou Défense du très ilustre Prince Guillaume, mandada escribir por Guillermo de Orange, líder de la Revuelta de los Países Bajos, y que se leyó

51 Hays, Memoirs... p. 377.

52 Hays, Memoirs... p. 377.

53 Perez, La leyenda negra, p. 65.

54 Maltby, La leyenda negra, pp. 63-64.

55 Hays, Memoirs... p. 379. 
en las Cortes Generales de Gante en diciembre de 1580. En este escrito las acusaciones contra España se centran en tres aspectos: los ataques personales contra Felipe II, el fanatismo e intolerancia religiosos de los espańoles y la matanza de los indios en América ${ }^{56}$.

Así, Felipe II será el blanco de todos los ataques de Inglaterra contra la España católica y su vileza será acentuada de forma singular en las biografías que ofrece Hays de dos de sus esposas: María Tudor e Isabel de Francia o de Valois. Resulta llamativo que en su primera colección Hays no incluyera a la reina inglesa María Tudor, aunque sí lo hace en su posterior compilación de reinas. Al tratarse de una de las reinas peor tratadas en Memoirs of Queens, quizá la escritora inglesa la consideró sin dignidad suficiente para incluirla en Female Biography. En cualquier caso el esposo de María, el rey español Felipe II, le sirve a Hays para empeorar más si cabe el retrato de esta reina: "Narrow in her intellects, superstitious in her piety, gloomy in her temper, and wedded to a man many of whose qualities too much resembled her own, she was unhappy in herself, and a scourge to the nation" 57 . De este modo esta escritora no hace sino reproducir estereotipos que se podían leer en libros de historia y otros tratados, como el que ella misma cita, "Fox's Acts and Monuments", es decir, Actes and Monuments of these Latter and Perillous Days, Touching Matters of the Church (1563) de John Fox, conocido como The Book of Martyrs, una colección anticatólica muy popular de persecuciones contra protestantes con numerosas ediciones y reediciones a lo largo de los siglos y también en la época de Hays. Además, se trata indudablemente, como señala García Cárcel, de una de las fuentes clásicas y por tanto más decisivas en el desarrollo de la Leyenda Negra ${ }^{58}$.

En cuanto a Isabel de Francia (1545-1568), tercera esposa de Felipe II, se puede observar que su biografía en los textos de Hays examinados en este trabajo se centra claramente en un episodio que igualmente contribuyó de forma relevante al desarrollo de la Leyenda Negra contra Espańa. Este suceso se refiere al apresamiento y muerte en extrañas circunstancias de Don Carlos, hijo de Felipe II y príncipe de Asturias, que fueron atribuidos a su propio padre en la propaganda antiespañola del momento. En primer lugar, se indica cómo se produjo el compromiso entre el rey español e Isabel: "Attracted by the beauty of the ill-fated Elizabeth, he scrupled not to dissolve the engagement of the lovers, and to solicit for himself the hand of the princess" 59 . Según consta en Female Biography, que es mucho más explícita a la hora de culpar al padre, su hijo no se lo perdonó y todos los conflictos entre padre e hijo se limitan a mencionar la ruptura amorosa causa-

56 Perez, La leyenda negra, pp. 78-82; García Cárcel, La leyenda negra, pp. 36-37.

57 Hays, Memoirs... p. 375.

58 García Cárcel, La leyenda negra, pp. 35-36.

59 Hays, Memoirs... pp. 306-307. 
da por el rey y los celos de este. En cualquier caso, su muerte levantó sospechas: "The particulars of the unhappy fate of don Carlos are involved in obscurity: he expired prematurely in the bloom of life, but whether by natural or violent means is uncertain. It was suspected, that, jealous of his attachment to the queen, Philip had given orders for the private execution of his son" 60 .

Estos acontecimientos históricos adquieren en los textos de Hays tintes románticos, y en vez de apelar a motivos políticos, como las necesarias alianzas entre potencias europeas, el matrimonio entre Felipe II e Isabel de Francia es consecuencia de la lujuria del rey, que se inmiscuye en la pareja de jóvenes enamorados. La trágica muerte de la reina tan solo diez semanas después de la del príncipe dio lugar a más sospechas y conjeturas, y Hays se hace eco de algunas de ellas, como las expuestas por diversos autores franceses. Cita en concreto a Brantome: "On parle fort sinistrément de sa mort”, y De Thou y el Abbé de St. Peal, que insinuaron que la muerte de la reina pudo haberse acelerado ${ }^{61}$ No deja de ser una hipótesis, pero Hays no duda en describir el carácter y naturaleza de Felipe II como cruel, severo y taciturno, en tanto que prueba de la posibilidad de que estos acontecimientos sucedieran en realidad. ${ }^{62}$ Estas son algunas de las razones para que Hays considere a esta reina "a victim to state policy" y "a sad and memorable example" ${ }^{63}$. Entre los diversos instrumentos propagandísticos utilizados para atacar a España, el supuesto filicidio cometido por Felipe II, e incluso la muerte también de su esposa por celos ante un posible romance con su hijo, resultaron especialmente productivos, como lo fueron también en el ámbito artístico y literario.

En la biografía de Isabel I de Inglaterra el soberano español vuelve a aparecer, en esta ocasión como uno de sus peores enemigos al tratar de derrotar a la reina inglesa una y otra vez. Su relación no obstante comenzó de forma incluso prometedora, pues se dice que Felipe fue el salvador de Isabel al interponerse a los designios de su esposa María Tudor cuando era reina de Inglaterra, ya que había considerado ejecutar a su hermanastra ${ }^{64}$. Además, el rey español le propuso matrimonio, una propuesta que la reina rechazó, como hizo con todas las que recibió. ${ }^{65}$ Pero estos dos monarcas estaban destinados a mantener una rivalidad sin igual, al ser ella "the bulwark of the protestants", mientras "Philip hoped to

60 Hays, Female... IV, pp. 298-299.

61 Hays, Female...IV, p. 299. Hays cita al final de la entrada dedicada a Isabel de Francia en Female Biography al mismo Brantome como fuente utilizada para la misma. Se trataría probablemente de una edición del siglo XVIII de sus Euvres du Seigneur de Brantome. Nouvelle édition, considerablement augmentée, revue, accompagnée de remarques historiques \& critiques, \& distribuée dans un meilleur ordre (1779).

62 Hays, Female... IV, p. 299, Hays, Memoirs... p. 307.

63 Hays, Memoirs... p. 306.

64 Hays, Female... IV, p. 76.

65 Hays, Memoirs... pp. 291-292. 
reunite the whole Christian world under the Catholic banner" 66 para lo que debía conquistar Inglaterra. Evidentemente había otras razones, con toda probabilidad más relevantes que la religión, que llevaron a Felipe a decidir invadir Inglaterra, sin embargo Hays subraya la oposición religiosa entre los dos reinos. Describe al soberano español como un católico fanático y una víctima de la superstición - un retrato que coincide casi plenamente con la visión que el resto de Europa también tenía de los españoles en general. Destaca el episodio siguiente:

An accident had contributed to inflame the bigotry of Philip. Having escaped, on a voyage, a violent tempest, he threw himself on his knees, on his arrival in the harbour, and vowed to the God of mercy, that a life, thus saved by his providence, should be devoted for the future to the extirpation of heresy. Nor did his subsequent conduct prove him perjured. In his zeal for the faith he spared neither age, sex, nor condition. Not less politic than intolerant, by placing himself at the head of the catholic party, he converted the zealots of the ancient church into partisans of the Spanish greatness; and by powerful allurement of religion, seduced from their allegiance the subjects of the neighbouring nations. ${ }^{67}$

La reina Isabel de Inglaterra es más moderada y de principios menos severos ${ }^{68}$, aunque siempre teniendo en cuenta que ella también estaba influenciada por los prejuicios religiosos de una época en que "religion was the moving spring" ${ }^{\text {"69 }}$.

Con el tiempo los preparativos para la invasión española de Inglaterra dieron comienzo. Se trataba de la Armada Invencible, descrita por Hays con calificativos como: "great preparations", "uncommon force and magnitude", "more formidable nature", "glorious enterprise", "extraordinary preparations"70, "vessels of uncommon seize and force", "officers of such consummate skill"71, simbolizando el poder alcanzado por la monarquía hispana, especialmente si se compara con la armada y las tropas inglesas, con un total de efectivos mucho menor y por tanto en total desventaja ${ }^{72}$. Así, para combatir a este poderoso enemigo se necesitaba un líder firme y decidido, como lo era la reina inglesa:

[Elizabeth's] energy and prudence called forth every resource

66 Hays, Memoirs... p. 298.

67 Hays, Female... IV, p. 103.

68 Hays, Female... IV, p. 103.

69 Hays, Female... IV, p. 159.

70 Hays, Memoirs... pp. 298-299.

71 Hays, Female... IV, pp. 207-208.

72 Hays, Female... IV, pp. 208-209. 
which her situation afforded, while her spirit, and the cool fortitude which she displayed, animated the people to resistance. The English catholics [sic] united with the protestants for the public defence, party distinctions were forgotten, all ranks of men prepared to oppose with vigour the attack of a foreign enemy. ${ }^{73}$

Aunque como es sabido, la flota española no pudo alcanzar las costas británicas por diversas razones que Hays señala en sus textos, la derrota de la Armada Invencible es uno de los más gloriosos episodios de la historia de Inglaterra y que por ello ha sido rescatado cuando posteriores momentos históricos difíciles así lo requerían para levantar los ánimos ${ }^{74}$.

\subsection{América y la población nativa}

La matanza de indígenas en América es otra de las acusaciones que sostienen la Leyenda Negra americana contra España. Se considera al Padre Bartolomé de las Casas como el principal creador de la misma, pues fue primordialmente tras la publicación de su Breve relación en 1552, cuando Guillermo de Orange y otros autores de escritos propagandísticos contra España se manifestaron con indignación sobre el comportamiento cruel y salvaje de los españoles en América. Sin embargo, tras todo este discurso sobre la falta de integridad y moralidad en la conducta de los españoles, se podía advertir un interés por minar la hegemonía española, de igual modo a los casos vistos anteriormente. La cuestión es que a partir de este momento las sucesivas traducciones y ediciones de la obra de Las Casas, así como otros escritos sobre este tema gozaron de gran predicamento en Europa, difundiéndose así una imagen de los españoles como brutales e inhumanos frente a seres inferiores e indefensos a los que masacraron. Más adelante, en el siglo XVIII se produce un enorme interés por el continente americano entre los ilustrados europeos, quienes darán continuidad a la polémica y examinarán la realidad americana desde diversas perspectivas, como los debates sobre la naturaleza de los nativos americanos o sobre la labor colonial en este continente ${ }^{75}$.

Por lo que se refiere a Hays, las referencias a estos acontecimientos son escasas. En la biografía de Isabel de Castilla en Memoirs of Queens, se menciona el descubrimiento de América por Colón auspiciado por ella en estos términos:

Isabella, in the events that followed, appears in a more amiable and respectable character. The idea of another hemisphere, or great western continent, having been conceived by Christopher Colum-

73 Hays, Memoirs... p. 299.

74 Maltby, La leyenda negra, p. 97; Saglia, Poetic Castles, pp. 41-42.

75 García Cárcel, La Leyenda Negra, pp. 296-297. 
bus, a Genoese navigator, who had studies the figure of the earth, he, after applying in vain to his countrymen and to Portugal for means to verify the truth of his theory, laid his views before the court of Spain. Here also he was exposed to neglect, and to those insults and contumelies "which patient merit from the unworthy take." [...] Inspired by the ambition of patronizing an undertaking so grand and imposing, she appeared to catch a portion of the enthusiasm of the projector, and offered to pledge her jewels to furnish him with a fleet. Her zeal and generosity overpowered every difficulty, and Columbus, through her aid, effected his arduous purpose, was crowned with success, and has been recompensed with a never dying fame. ${ }^{76}$

A continuación se indica que tras el descubrimiento Fernando e Isabel, gracias a una bula papal, fueron los dueños de las tierras descubiertas a partir de 100 leguas al oeste de las Azores. Y para finalizar este relato sobre el descubrimiento de América Hays vuelve a centrarse en Colón, el verdadero protagonista del mismo, más que la reina, remarcando la ingratitud de la que fue objeto el insigne navegante, a pesar de la relevancia de su gesta. Es precisamente este hecho el que se resalta aquí, la importancia del descubrimiento de este nuevo continente. A pesar de que se habla de las posesiones de la Corona española en América, se puede entrever también el valor que esta hazaña colombina tuvo para el resto de países europeos, que posteriormente también fueron llegando a América y la colonizaron, como la corona inglesa o francesa, en el norte del continente. Estos acontecimientos se describen como algo muy positivo, concretamente como una magnífica e impresionante empresa, tras una ardua tarea ${ }^{77}$, sin mencionar en ningún momento las consecuencias para la población nativa. De igual modo, en la biografía de María de Estrada, la española que luchó junto a su marido en las filas de Cortés durante la conquista de México, Hays únicamente ensalza sus hazañas y valor, y la admiración que causó entre los que la rodeaban, sin aludir tampoco en este caso a los pobladores nativos.

Para poder vislumbrar a la población indígena del nuevo continente tenemos que dirigirnos a la biografía de Matoaks o Pocahontas, la única nativa americana biografiada por Hays. En la breve semblanza de esta mujer, se destaca que aun perteneciendo a una tribu de los primeros pobladores de Virginia, se convirtió al cristianismo y adoptó la cultura de los colonizadores. En el último fragmento de esta biografía se dejan ver claramente cuáles son los méritos por los que Matoaks merece aparecer como integrante de la galería de mujeres que muestra Hays, y no

76 Hays, Memoirs... pp. 329-330.

77 Hays, Memoirs... p. 330. 
son otros que el abandono de la barbarie de su cultura nativa por la civilización de los colonizadores llegados de Europa: "Her good sense raised her above the prejudices of her education, and the barbarous customs of her country: her humanity and generosity reflect honour upon her memory. She was the first Virginian that learned to speak English, and that embraced the tenets of the Christian church"78.

Hays se aparta por tanto de otros autores del siglo XVIII y XIX que ofrecían una imagen idealizada de los pueblos indígenas, con el ya famoso arquetipo del noble salvaje propuesto por Rousseau, y por ello mantenían que los nativos habían mantenido su pureza por no haber sido alcanzados por la civilización; o de aquellos otros que, aunque consideraban a los habitantes del nuevo continente como inferiores a los europeos, creían que eran por ello más débiles y desvalidos y necesitaban protección ${ }^{79}$. Hays debía de estar al tanto de estas teorías, pues se debatían en círculos disidentes radicales como los que ella frecuentaba ${ }^{80}$; sin embargo, en sus textos no profundiza en este tema y ofrece un punto de vista sobre los habitantes nativos americanos totalmente tradicional y eurocentrista.

\section{Mito ROMÁNtico}

Con la llegada del Romanticismo llegó también el género gótico, que como se ha visto más arriba, mostraba especial predilección por la Inquisición española, dadas las posibilidades estilísticas que ofrecía este tema a los escritores y escritoras, con numerosas escenas en lugares lúgubres y tenebrosos, junto a la angustia y terror que ocasionaban los inquisidores en su numeroso público. Este nuevo movimiento provocó asimismo la sublimación literaria de ciertos temas de las historia de España que se prestaban a ello, como el del Infante Don Carlos, descrito dentro del epígrafe dedicado a Felipe II, un proceso que ya había comenzado en el siglo anterior con Alfieri y su Filippo (1783) y la tragedia Don Carlos (1787) de Friedrch Schiller ${ }^{81}$. En estos y otros textos sobre este mito, que contribuyeron a su popularidad en Europa, se centran en el triángulo amoroso conformado por una pareja joven e inocente, frente al rey, un personaje siniestro que parece surgido de una novela gótica. Por lo que tanto Hays como sus lectoras conocerían estos temas e intrigas y estarían familiarizadas con ellos, y así la escritora inglesa

78 Hays, Female... V, p. 500.

79 García Cárcel, La Leyenda Negra, p. 295.

80 Paula R. Feldman, "Introduction", en Helen M. Williams: Peru and Peruvian Tales. Peterborough, Canadá: Broadview editions, 2015, pp. 11-35.

81 Para la utilización que se hace por parte de historiadores de diversas épocas y países de la figura de don Carlos, véase Ricardo García Cárcel, "Felipe II y la leyenda negra en el siglo XIX", en José Martínez Millán y Carlos Reyero (eds.): El siglo de Carlos Vy Felipe II. La construcción de los mitos en el siglo XIX, vol. I. Madrid: Sociedad Estatal para la Conmemoración de los Centenarios de Felipe II y Carlos V, 2000, pp. 353-371; Ricardo García Cárcel, "La construcción de un mito", en La Aventura de la Historia, Dossier: Don Carlos el principe de la Leyenda Negra, vol. 38 (2001), pp. 15-19. También Saglia, Poetic Castles, pp. 31-32; Moreno, La invención, pp. 166-167. 
aprovechará las biografías de algunas de las reinas para explotar ella también las mismas cuestiones.

En muchas de las versiones románticas de esta trama familiar que envolvía a la monarquía española del siglo XVI, tanto Felipe II como su hijo Don Carlos aparecen retratados como héroes románticos, solitarios, atormentados, incomprendidos, y conscientes de ello, pero que no dejan de perseguir sus ideales, que evidentemente no coinciden con los del otro y por ello colisionan, de ahí que todo desemboque en tragedia. Por otra parte, en esta caracterización de estos dos personajes históricos se funden también muchos de los rasgos que en la época romántica se atribuía a los espańoles y que configuraron un modelo que se distinguía por la valentía, la pasión, los celos, en suma, todos los atributos de un caballero español. Hays se refiere a este prototipo de forma explícita en la biografía de la reina Ana de Austria, pues esta, por ser de origen español, cuando llega por primera vez a la corte francesa, una vez casada con el delfín de Francia, tuvo ciertos problemas de adaptación, que la escritora inglesa atribuye al espíritu caballeresco que durante el Romanticismo se aceptaba como representativo de los españoles ${ }^{82}$ :

It is not extraordinary that a Spanish princess should have imbibed the maxims and the spirit of chivalry: Anne of Austria was peculiarly tenacious of the importance and authority of her sex, of which she formed her opinions upon the model of the heroic ages. Women, she was persuaded, were formed to be adored and served by the men: nor did she reprove those who presumed to declare themselves her lovers: she considered their homage as the privilege due to her sex, to her rank, and to her charms. ${ }^{83}$

Sin embargo, tras un periodo en dicha corte, Ana fue capaz de asumir "a dignified conduct" y olvidar "the follies of gallantry" 84

\section{Conclusión}

Como se ha podido observar a lo largo de este trabajo, la presencia de varios temas asociados tradicionalmente con la Leyenda Negra contra España es significativa en las dos colecciones biográficas de Hays, especialmente en las biografías de las reinas de origen español de ambos textos, dada la rivalidad entre las diferentes naciones europeas por la supremacía en el continente y también en los nuevos territorios americanos conquistados. Es curioso que, aunque se trate de dos textos cuyo eje vertebrador lo constituyen las mujeres, pues ellas son las protagonistas, la 
presencia de hombres es muy relevante. No debemos olvidar que habitualmente a lo largo de la historia la vida de las mujeres ha adquirido transcendencia y se ha considerado merecedora de ser contada por algún tipo de relación con un hom$b^{85}{ }^{85}$. Un aspecto mucho más decisivo en el caso de las mujeres de la realeza, que han pasado a la historia, salvo alguna excepción notable, por ser hijas, esposas o madres de reyes. Por ello dos de los personajes en los que se ha centrado la Leyenda Negra, el emperador Carlos y sobre todo el rey Felipe II, adquieren un papel relevante en algunas biografías de mujeres con las que tuvieron relación familiar pero también política. Será con ellos con quienes surgen cuestiones relacionadas con este tema, como la persecución de protestantes, la derrota de la Armada Invencible o la sospechosa muerte del Infante Don Carlos. El tratamiento de los mismos por parte de Hays es el tradicionalmente asociado a la propaganda contra España, y también resulta esclarecedora la perspectiva que adopta la escritora inglesa con respecto a la conquista y colonización de América y su opinión sobre los habitantes nativos de estos territorios. En este sentido, los materiales utilizados por Hays como fuente para la creación de sus biografías pueden resultar decisivos, pues se ha señalado que en estos textos la escritora abandonó las ideas más radicales y liberales expuestas en sus obras anteriores, y adoptó un posicionamiento y tono más conservadores, adaptándose así mejor al ambiente postrevolucionario reinante en la Gran Bretaña de principios del siglo XIX ${ }^{86}$.

Por otro lado, estos dos textos son también reflejo de la época en que se publicaron y presentan por tanto ciertas pinceladas románticas, particularmente en aquellas alusiones relacionadas con el ideal de caballero español. En la época en que Hays escribe y publica sus obras España ya no es una nación pujante y poderosa, sino que está en total decadencia y es una mera sombra de lo que fue, y así lo constatan los viajeros que pasaron por la península ${ }^{87}$ y se hacen eco de ello también en relatos de ficción ${ }^{88}$. De manera que España no es ya un enemigo al que temer, no es necesario demonizarlo, y los autores y autoras ingleses se van a centrar en una cuestión que no abordó Hays de forma explícita, la decadencia de España. Describen un imperio en ruinas y su interés se dirige a determinar las causas que lo han llevado a esta situación para no repetirlas, pues son los británicos quienes en estos momentos han alcanzado la supremacía y se encuentran en

85 P. R. Backscheider, Reflections on Biography. Oxford: Oxford University Press, 2001, p. 144. 86 Gary Kelly, Women, Writing and the Revolution 1790-1827. Oxford y Nueva York: Oxford University Press, 1997, p. 234; Spongberg, Writing, p. 117.

87 Véase, por ejemplo, María Antonia López Burgos, Granada. Relatos de viajeros ingleses (1809-1830). Melbourne: Australis, 2000.

88 Véase, por ejemplo, Begoña Lasa Álvarez, “The Insecure and the Irrational: The Southern European Other in The Tradition of the Castle; or, Scenes in the Emerald Isle (1824) by Regina Maria Roche", en JES - Journal of English Studies, vol. 12 (2014), pp. 71-94. 
plena expansión de su gran imperio ${ }^{89}$. En cualquier caso, se incide de nuevo en la religión como causa para justificar el ocaso de España, en particular se mencionan la superstición y la irracionalidad del catolicismo. Por lo tanto, aunque no exactamente desde el mismo punto de vista, la imagen de Espańa ofrecida por Hays en sus colecciones biográficas se inscribiría también en esta corriente al incidir en aquellos aspectos especialmente oscuros y negativos de su historia.

89 Howarth, The invention, pp. 1-28; Irving A. Anthony Thomson, "Aspectos del hispanismo inglés y la coyuntura internacional en los tiempos modernos (siglos XVI-XVIII)", en Obradoiro de historia moderna, vol. 15 (2006), pp. 25-26. 
